\title{
Kinetics, Thermodynamics and Isothermal Modelling of Liquid Phase Adsorption of Methylene Blue onto Moringa Pod Husk Activated Carbon
}

\author{
G.B. Adebayo, ${ }^{a, *}$, W. Jamiu, , H.K. Okoro ${ }^{a, *}$, F.O. Okeola ${ }^{a}$, A.K. Adesina ${ }^{a}$ and O.A. Feyisetan ${ }^{b}$ \\ ${ }^{a}$ Analytical-Environmental \& Material Science Research Group, Department of Industrial Chemistry, \\ Faculty of Physical Sciences, P.M.B. 1515, University of Ilorin, 240003 Ilorin, Nigeria. \\ ${ }^{b}$ Department of Chemistry, Federal University of Technology, Minna, Nigeria. \\ Received 24 December 2018, revised 1 July 2019, accepted 7 October 2019.
}

\begin{abstract}
This study focused on the liquid phase sorption of methylene blue (MB) using low cost agro-waste from moringa pod husks. Moringa pod husk was carbonized at $450{ }^{\circ} \mathrm{C}$ for $30 \mathrm{~min}$, which was later activated with $0.1 \mathrm{M}$ phosphoric acid. The physico-chemical properties of moringa pod activated carbon (AMP) were determined. The results of the physicochemical parameters are: moisture content $(13.6 \pm 0.02)$, ash content $(2.61 \pm 0.11)$, point of zero charge $\left(\mathrm{pH}_{\mathrm{ZPC}}\right)(7.2)$ and bulk density $\left(0.6 \mathrm{~g} \mathrm{~L}^{-1}\right)$. The sample was also characterized using Brunaeur Emmett Teller (BET), scanning electron microscopy (SEM), energy dispersive X-ray spectroscopy (EDX) and Fourier-transform infrared spectroscopy (FTIR). The BET surface area obtained for AMP is $1340.234 \mathrm{~m}^{2} \mathrm{~g}^{-1}$. The effect of optimized parameters such as initial concentration, contact time, $\mathrm{pH}$, adsorbent dosage, and temperature on methylene blue removal was investigated. The obtained maximum monolayer adsorption capacity value $\left(q_{\max }\right)$ is $9.5785 \mathrm{mg} \mathrm{g}^{-1}$. The three adsorption isotherm models, namely Langmuir, Freundlich and Temkin, were employed to describe the fitness of equilibrium data. The Langmuir equation fitted the adsorbent system better with a $R^{2}$ value of 0.9958 . The pseudosecond-order kinetic equation also fitted the data well. Thermodynamic studies showed that the AMP-MB adsorption system is spontaneous and endothermic as a negative and positive value was obtained for $\Delta \mathrm{G}^{0}\left(-0.460 \mathrm{KJ} \mathrm{mol}^{-1}\right)$ and $\Delta \mathrm{H}^{0}\left(4.482 \mathrm{KJ} \mathrm{mol}^{-1}\right)$, respectively.
\end{abstract}

KEYWORDS

Moringa pod husks, characterization, methylene blue, adsorption kinetics, adsorption models.

\section{Introduction}

In recent years, synthetic dyes have often been used in various industrial dyeing and printing processes. The textile industry is the largest consumer of synthetic dyes utilizing about $56 \%$ of the total world dye production per annum of $7 \times 10^{5} \mathrm{t}$. ${ }^{1}$ During the textile dyeing process, released untreated effluent may contaminate water bodies which poses a great threat to aquatic organisms and the people who use these water bodies for living purposes. In a water supply system, when a concentration as low as just $1.0 \mathrm{mg} \mathrm{L}^{-1}$ of dye is present in the water supply, it could be dangerous for human consumption. ${ }^{2}$

Physical and chemical properties of water such as the colour, taste, odour, alkalinity, acidity, etc., are affected when these dyes are present. Other effects include: toxicity to aquatic life, mutation of DNA, carcinogenicity, and damage to some vital organs in human beings, such as dysfunction of the kidneys, reproductive system, liver, brain and central nervous system. ${ }^{3}$ Dyes possess complex aromatic structures and therefore they may not be biodegradable.

The treatment of these water bodies before water consumption is very important. A broad number of reported methods, e.g. $\mathrm{UV} / \mathrm{H}_{2} \mathrm{O}_{2}$ oxidation, adsorption, flocculation, precipitation, micro-filtration, and membrane separation processes have been applied in the removal of dyes from water. ${ }^{4-5}$ Despite the reported treatment methods, adsorption has been found to be

* To whom correspondence should be addressed.

E-mail: hkoadeola@gmail.com / okoro.hk@unilorin.edu.ng more useful in the removal of contaminants from wastewater. Adsorption has some advantages over other methods of treatment which include low cost regeneration, known process equipment, non-sludge system operation and adsorbate recovery. ${ }^{6}$

Owing to the high cost of production of activated carbon industrially, activated carbon from agricultural wastes such as orange peel, moringa seed, cashew nut, neem seed, coconut husk rice husk, almond seed, etc. ${ }^{7-8}$, are now being considered for adsorbing contaminants onto their surfaces. These natural materials are cheap, can be produced in large quantities, and have good sorption capacity.

Therefore, this work is aimed at sorption of methylene blue from aqueous solution onto activated carbon from moringa pods.

\section{Experimental}

\subsection{Sampling and Preparation of Adsorbent}

Moringa pod (MP) husks were largely collected from the grounds of the University of Ilorin, Ilorin, Nigeria. They were washed with running tap water to remove impurities in the form of sand, dust, soluble and coloured components. The moringa pods were then dried in an oven at $110^{\circ} \mathrm{C}$ for $4 \mathrm{~h} . .^{9}$ The dried moringa pods were pulverized with mortar and pestle to reduce the size. $50 \mathrm{~g}$ of the ground MP was impregnated for $24 \mathrm{~h}$. with $200 \mathrm{~mL}$ of $0.1 \mathrm{M}$ of phosphoric acid to form 1:4 of impregnation ratio; after 24 hours of impregnation, the excess 
acid was decanted and the material was pyrolyzed in a muffle furnace at $723 \mathrm{~K}$ for $30 \mathrm{~min}^{2}$

The prepared activated MP was washed with $200 \mathrm{~mL}$ of distilled water to remove the activating agent $\left(\mathrm{H}_{3} \mathrm{PO}_{4}\right)$ used for impregnation. The washing was continued until $\mathrm{pH}$ of between 6.5 and 7 was achieved. It was oven-dried at $105{ }^{\circ} \mathrm{C}$ for $4 \mathrm{~h}$ to constant weight. ${ }^{10}$ The dried sample was sieved with $0.05 \mathrm{~mm}$ mesh to obtain fine powdered activated carbon denoted as AMP. The activated carbon moringa pods (AMP) were kept in airtight vials and used for further studies.

\subsection{Batch Adsorption Experiments}

A stock solution of $100 \mathrm{mg} \mathrm{L}^{-1}$ methylene blue was prepared and standard working concentrations ranging from $5-100 \mathrm{mg} \mathrm{L}^{-1}$ were prepared by serial dilution of appropriate volumes from the stock. The stock solution was scanned with a Beckmann Coutler UV-visible spectrophotometer to obtain maximum wavelength $(\lambda \max =682 \mathrm{~nm})$ at peak absorbance.

A batch adsorption study was done in order to determine the effect of optimum conditions such as $\mathrm{pH}$, contact time, adsorbent dose and initial concentration of the dye solution. The effect of $\mathrm{pH}$ on the dye was carried out using $0.1 \mathrm{M} \mathrm{HCl}$ and $0.1 \mathrm{M}$ $\mathrm{NaOH}$, whereas the adsorbent dose and contact time were carried out by varying the quantity of the adsorbents and time, respectively. The temperature was varied between $30{ }^{\circ} \mathrm{C}$ and $80^{\circ} \mathrm{C}$. From the conducted experiments, the optimum parameters were obtained and were used for further studies. The quantity of the dye adsorbed was calculated using Equations 1 and 2, respectively.

$$
\begin{aligned}
& \% \text { Sorption }=\frac{\mathrm{C}_{1}-\mathrm{C}_{\mathrm{e}}}{\mathrm{C}_{1}} \times 100 \\
& \mathrm{Q}=\frac{\mathrm{C}_{1}-\mathrm{C}_{\mathrm{e}}}{\mathrm{M}}
\end{aligned}
$$

where $\mathrm{Q}=$ quantity of solute adsorbed in $\left(\mathrm{mg} \mathrm{g}^{-1}\right), \mathrm{V}=$ specific volume of the adsorbate $(\mathrm{L}), \mathrm{C}_{\mathrm{i}}=$ concentration of adsorbate before adsorption $\left(\mathrm{mg} \mathrm{L}^{-1}\right), \mathrm{C}_{\mathrm{e}}=$ concentration after adsorption $\left(\mathrm{mg} \mathrm{L}^{-1}\right)$ and $\mathrm{M}=$ mass of the adsorbent used $(\mathrm{g})$.

\subsection{Adsorption Isotherm}

Langmuir, Freundlich and Temkins equations were employed to study the adsorption isotherms of the dye.

\subsubsection{Langmuir Isotherm Model}

When the Langmuir equation was linearized, Equation 3 was obtained

$$
\frac{\mathrm{C}_{\mathrm{e}}}{\mathrm{q}_{\mathrm{e}}}=\frac{1}{\mathrm{~K}_{\mathrm{L}} \mathrm{q}_{\mathrm{m}}}+\frac{\mathrm{C}}{\mathrm{q}_{\mathrm{m}}}
$$

where $C_{e}$ represents the equilibrium concentration of methylene blue $\left(\mathrm{mg} \mathrm{L}^{-1}\right), \mathrm{q}_{\mathrm{e}}$ is the equilibrium quantity of methylene blue adsorbed onto the adsorbent $\left(\mathrm{mg} \mathrm{g}^{-1}\right), \mathrm{q}_{\mathrm{m}}$ represents the monolayer maximum adsorption capacity of adsorbent $\left(\mathrm{mg} \mathrm{g}^{-1}\right)$ and $\mathrm{Kl}$ is the Langmuir adsorption constant $\left(\mathrm{L} \mathrm{mg}^{-1}\right) .{ }^{11}$

\subsubsection{Freundlich Isotherm Model}

This linearized equation can be expressed in term of a logarithmic form as follows:

$$
\log \mathrm{Q}=\log \mathrm{K}_{\mathrm{f}}+\frac{1}{\mathrm{n}} \log \mathrm{P}
$$

When the $\log Q$ is plotted against $\log P$, the slope of $1 / n$ and an intercept of $\log \mathrm{K}_{\mathrm{f}}$ were obtained. Hence, from the intercept and slope of the linear plot, $\mathrm{K}_{\mathrm{f}}$ and $\mathrm{n}$ can be calculated.

\subsubsection{Temkin Isotherm Model}

The assumption of this model is based on heat of adsorption (function of temperature) in which all layers of the molecules would decrease linearly when the lowest and largest value of concentration is ignored. ${ }^{12}$

$$
\mathrm{q}_{\mathrm{e}}=\mathrm{B} \ln \mathrm{A}_{\mathrm{T}}+\mathrm{B} \ln \mathrm{C}_{\mathrm{e}}
$$

where $A_{T}$ represents the Temkin equilibrium binding constant $\left(\mathrm{L} \mathrm{g}^{-1}\right)$, and $\mathrm{B}$ and $\mathrm{k}_{\mathrm{f}}$ are the constants of the Temkin isotherm. $\mathrm{B}=\mathrm{RT} / \mathrm{b}$ and $\mathrm{T}$ represents temperature $(\mathrm{K})$.

\subsection{Adsorption Kinetics}

The sorption kinetics describes the rate at which the solute is taken up by the adsorbent, which in turn controls the time of sorption to take place. It is an important characteristic used to express the power of adsorption. ${ }^{13}$

In this study, the kinetics liquid phase sorption of methylene blue onto activated carbon from moringa pod husk (AMP) was tested with different adsorption kinetics models, including Lagergren pseudo-first-order and pseudo-second-order equations.

\subsubsection{Pseudo-First-Order Equation}

This model of adsorption kinetics and can be expressed by the following equations.

$$
\frac{\mathrm{dqt}}{\mathrm{dt}}=\mathrm{k}_{1}\left(\mathrm{q}_{\mathrm{e}}-\mathrm{q}_{\mathrm{t}}\right)
$$

where $\mathrm{q}_{\mathrm{e}}$ and $\mathrm{q}_{\mathrm{t}}$ are the adsorption quantity at equilibrium and time $\mathrm{t}$, respectively $\left(\mathrm{mg} \mathrm{g}^{-1}\right)$, and $\mathrm{k}_{1}$ is the adsorption pseudofirst-order rate constant $\left(\mathrm{min}^{-1}\right)$.

By integrating Equation 6 where boundary $t=0$ to $t=t$ and $\mathrm{q}_{\mathrm{t}}=0$ and $\mathrm{q}_{\mathrm{t}}=\mathrm{q}_{\mathrm{e}}$ was applied, the integrated form becomes:

$$
\log \left(\mathrm{q}_{\mathrm{e}}-\mathrm{q}_{\mathrm{t}}\right)=\log \left(\mathrm{q}_{\mathrm{e}}\right)-\frac{\mathrm{k}_{1} \mathrm{t}}{2.303}
$$

When $\log \left(q_{e}-q_{t}\right)$ against $t$ was plotted, a linear relationship graph was obtained, and constant $\mathrm{k}_{1}$ and $\mathrm{q}_{\mathrm{e}}$ can be determined from slope and intercept, respectively. ${ }^{14}$

\subsubsection{Pseudo-Second-Order Kinetics Equation}

This adsorption kinetic rate equation can be expressed as:

$\frac{\mathrm{dqt}}{\mathrm{dt}}=\mathrm{k}_{2}\left(\mathrm{q}_{\mathrm{e}}-\mathrm{q}_{\mathrm{t}}\right)^{2}$

$\mathrm{k}_{2}$ is the pseudo-second-order adsorption rate constant $\left(\mathrm{g} \mathrm{mg}^{-1} \mathrm{~min}^{-1}\right)$.

The linear form of Equation 8 can be written as follows:

$\left[\frac{\mathrm{t}}{\mathrm{q}_{\mathrm{t}}}\right]=\frac{1}{\mathrm{k}_{2} \mathrm{q}_{\mathrm{e}}^{2}}+\frac{1}{\mathrm{q}_{\mathrm{e}}}(\mathrm{t})$

From the linearity plot of $\left(t / q_{t}\right)$ against $t$, the $k_{2}$ and $q_{e}$ can be determined from the slope and intercept, respectively.

\subsection{Thermodynamic Studies}

The importance of thermodynamics in spontaneity and heat change of the adsorption route and parameters can be assessed through such parameters as free energy, enthalpy and entropy and the relationship which were calculated using the following equations. $^{15}$

$$
\begin{aligned}
& \Delta \mathrm{G}^{0}=-R T \ln \mathrm{K}_{\mathrm{c}} \\
& \Delta \mathrm{G}^{0}=\Delta \mathrm{H}^{0}-\mathrm{T} \Delta \mathrm{S}^{0}
\end{aligned}
$$

where $\mathrm{R}$ represents the universal gas constant $\left(8.314 \mathrm{~J} \mathrm{~mol}^{-1} \mathrm{~K}^{-1}\right)$ and $\mathrm{T}$ represents the temperature $(\mathrm{K})$. The change in enthalpy $\Delta \mathrm{H}^{0}$ and the change in the degree of disorderliness $\Delta \mathrm{S}^{0}$ can be calculated from the slope and intercept of the plot. 


\section{Results and Discussion}

The result of the physicochemical characterization are presented in Table 1 . The result of moisture content obtained could not have effect on the quantity of activated carbon adsorbed but apparently dilutes the carbon. ${ }^{16}$ The ash content obtained in this study for AMP (2.61\%) is higher compared to those reported by Sivakumar et al. ${ }^{17}(2.39 \%)$. It was attributed to lower inorganic content and high fixed carbon. ${ }^{18}$ Bulk density indicates the fibre content of the precursor. It was shown that the bulk density obtained for AMP (0.64) is almost the same by those obtained from Martynia annua L. by Sivakumar et al. ${ }^{17}(0.63)$.

Iodine number $\left(\mathrm{mg} \mathrm{g}^{-1}\right)$ and surface area $\left(\mathrm{m}^{2} \mathrm{~g}^{-1}\right)$ of 935 and 1340.234 was observed, respectively, with higher values than those reported for Hemidesmus indicus by Srihari and Ashutosh ${ }^{19}$, base-treated and carbonized rice husks by Wuana et al., ${ }^{20}$ banana empty fruit bunch and Delonix regia fruit pod by Sugumaran et al. ${ }^{21}$ The iodine number gives an idea of the total surface area of an adsorbent. It has been reported that adsorbents with high iodine number/surface area perform better in the removal of small-sized contaminants. ${ }^{22}$ The point of zero charge $\left(\mathrm{pH}_{\mathrm{ZPC}}\right)$ of AMP was obtained at 7.2. This implies that the prepared carbon is free from surface charges near neutral $\mathrm{pH}$. Hence the carbon sample is suitable for the treatment of water even at the neutral medium. ${ }^{12}$

Table 1 Physico-chemical characterization of activated carbon moringa pods (AMP).

\begin{tabular}{cll}
\hline Sample number & Properties & AMP \\
\hline 1 & Moisture content & $5.16 \pm 0.62$ \\
2 & $\%$ Ash content & $2.61 \pm 0.11$ \\
3 & Bulk density $/ \mathrm{g} \mathrm{L}^{-1}$ & 0.64 \\
4 & Surface area $/ \mathrm{m}^{2} \mathrm{~g}^{-1}$ & 1340.234 \\
5 & $\mathrm{pH}$ & $6.9 \pm 0.02$ \\
6 & $\%$ Yield & 65.28 \\
7 & $\mathrm{pH}_{\text {ZPC }}$ & 7.2 \\
\hline
\end{tabular}

\subsection{Instrumental Characterization of the Synthesized Adsorbent}

Different spectroscopic techniques were employed for characterizing the synthesized AMP adsorbent which includes BET, FTIR, SEM and EDX.

\subsubsection{Fourier Transform Infra Red Spectroscopy}

FTIR analysis was carried out in order to identify the different functional groups present in the adsorbent which may possibly be responsible for adsorption process. From the FTIR spectra shown in Fig. 1a, AMP shows a very broad peak at $3392.08 \mathrm{~cm}^{-1}$ which may be attributed to $\mathrm{OH}$ group stretching suitable for inter- and intra-molecular hydrogen bonding of polymeric compounds such as carboxylic acids, alcohols or phenols as in hemicellulose, cellulose and lignin. ${ }^{23}$ The peak observed at $2920.3 \mathrm{~cm}^{-1}$ may be attributed to $\mathrm{C}-\mathrm{H}$ of $\mathrm{sp}^{3}$. The band at $1701.32 \mathrm{~cm}^{-1}$ may be attributed to $\mathrm{C}=\mathrm{O}$ stretching of carbonyl group and also the band at $1606.33 \mathrm{~cm}^{-1} \mathrm{C}=\mathrm{C}$ stretching of alkene. After the adsorption experiments, there were obvious absorption band shifts from the spectral of the loaded adsorbent compared to the freshly prepared adsorbent. The absorption bands at $3382.59 \mathrm{~cm}^{-1}$ may be assigned to $\mathrm{OH}$ group stretching. Also, the band at $2923.48 \mathrm{~cm}^{-1}$ may be assigned to $\mathrm{C}-\mathrm{H}$ of $\mathrm{sp}^{3}$. The band at $1694.99 \mathrm{~cm}^{-1}$ may be attributed to the $\mathrm{C}=\mathrm{O}$ of carbonyl group as shown in Fig. 1b.

\subsubsection{BET Analysis}

The BET analysis was carried to establish the surface area of the adsorbent. Different BET methods that are used for the analysis are Multi-point Bet method and the surface area observed was $1432.923 \mathrm{~m}^{2} \mathrm{~g}^{-1}$. The micro-pore volume of $0.047 \mathrm{cc} \mathrm{g}^{-1}$ was obtained by the T plot method, micro-pore area of $92.689 \mathrm{~m}^{2} \mathrm{~g}^{-1}$ and external surface area of $1340.234 \mathrm{~m}^{2} \mathrm{~g}^{-1}$. The average halfwidth, adsorption energy, micro-pore volume and micro-pore surface area of AMP are given by DR method to be $14.827 \AA$, 8.768 $\mathrm{KJ} \mathrm{mol}^{-1}, 0.735 \mathrm{cc} \mathrm{g}^{-1}$ and $2067.371 \mathrm{~m}^{2} \mathrm{~g}^{-1}$, respectively.

\subsubsection{Energy Dispersive X-Ray (EDX)}

The EDX analysis gives a semi-quantitative analysis of the adsorbent. The EDX spectrum is shown in Fig. 2 and the percentage load of the element in each adsorbent is embodied in Table 2.

Table 2 Weight (\%) of element in AMP.

\begin{tabular}{ccc}
\hline $\mathrm{s} / \mathrm{n}$ & Elements & Weight $/ \%$ \\
\hline 1 & Carbon & 73.51 \\
2 & Oxygen & 26.49 \\
\hline
\end{tabular}

\subsubsection{Scanning Electron Microsocopy}

A surface morphology of activated carbon moringa pod (AMP) shown in Fig. 3a and Fig. 3b was carried out at different magnifications. The micrographs of the designated sample show the occurrence of irregular and highly porous surfaces. The existence of highly porous surface may be suitable for the evaporation of the activating agent $\left(\mathrm{H}_{3} \mathrm{PO}_{4}\right)$ used in the production of the activated carbon. ${ }^{24}$

\subsection{Adsorption Experiment Results}

\subsubsection{Effect of Initial Adsorbate Concentration}

This is one of the vital parameter to be determined as it enables us to know the optimum concentration at which the methylene blue could be adsorbed from aqueous medium. This effect was done as the solution concentration was varied between 5-80 $\mathrm{mg} \mathrm{L}^{-1}$ keeping parameters such as adsorbent dose, $\mathrm{pH}$, time and temperature constant. Fig. 4 represents the graph of effect of initial concentration. A noticeable boost in the adsorption capacity from $1.1695 \mathrm{mg} \mathrm{g}^{-1}$ to $9.0466 \mathrm{mg} \mathrm{g}^{-1}$ was observed until there was no any considerable alteration in the adsorption capacity. The highest percentage $(93.5593 \%)$ of dye removed was observed at $5 \mathrm{mg} \mathrm{L}^{-1}$ and the least percentage (51.3075\%) was observed at $70 \mathrm{mg} \mathrm{L}^{-1}$ in that order. This decline in the corresponding increment with adsorbate could be traced to the fact that the available pore volume of the adsorbents had been occupied thereby reducing the interaction between the adsorbents and the subsequent dye intake.

\subsubsection{Effect of Adsorbent Dose}

This is one of the crucial parameters which established the capability of an adsorbent for a specified concentration of methylene blue solution. From Fig. 5 it can be shown that the increases in the quantity adsorbed can be evidenced by the decrease in the mass of the adsorbent This alteration can be elucidated on the basis on the mass balance relationship in Equation 2 which shows that mass of adsorbent is inversely proportional to the adsorption capacity. ${ }^{25}$

A gradual boost in the percentage adsorbed also occurred as the adsorbent dose increases after which an additional increase in the adsorbent dose does not have impact on the dye removal. It has been reported elsewhere that as the adsorbent dose increases, the movement of dye ions to the energetic adsorption 

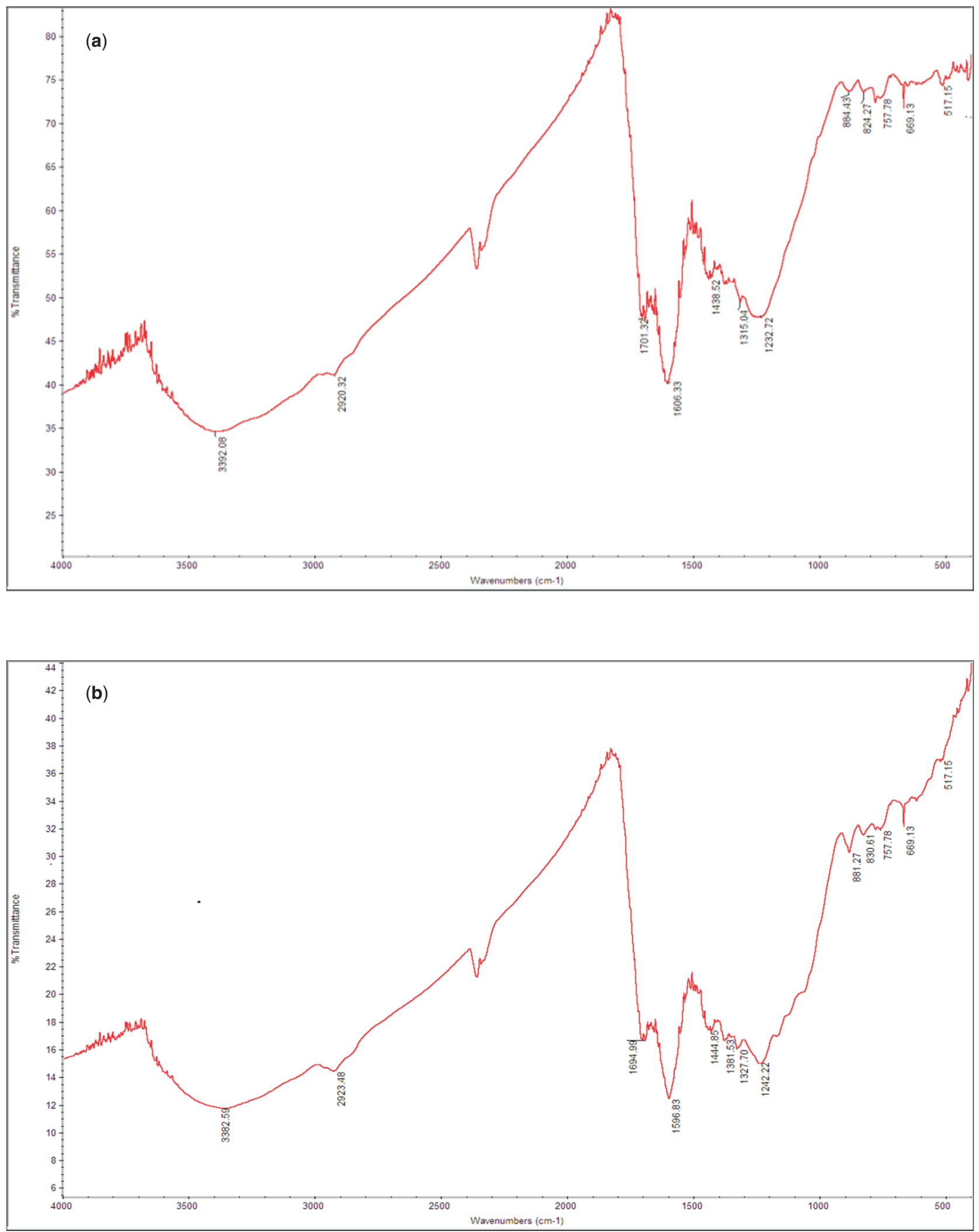

Figure 1 (a) FTIR spectra of activated carbon moringa pod (AMP) before adsorption. (b) FTIR spectra of activated carbon moringa pod (AMP) after adsorption.

sites will be restricted as well, hence reduced the adsorption efficiency. ${ }^{26}$

\subsubsection{Effect of Contact Time}

The role of contact time in the adsorption system is very essential irrespective of the other experimental parameters affecting the adsorption kinetics. ${ }^{27}$ The graph of the effect is represented in Fig. 6. In this study, it was observed that 60 min agitation time was sufficient to reach equilibrium which shows the highest percentage of adsorption unto the adsorbent.

There is an increase in the adsorption percentage of methylene blue from 73.2 to $77.2 \%$ for the first hour, but after some time, 


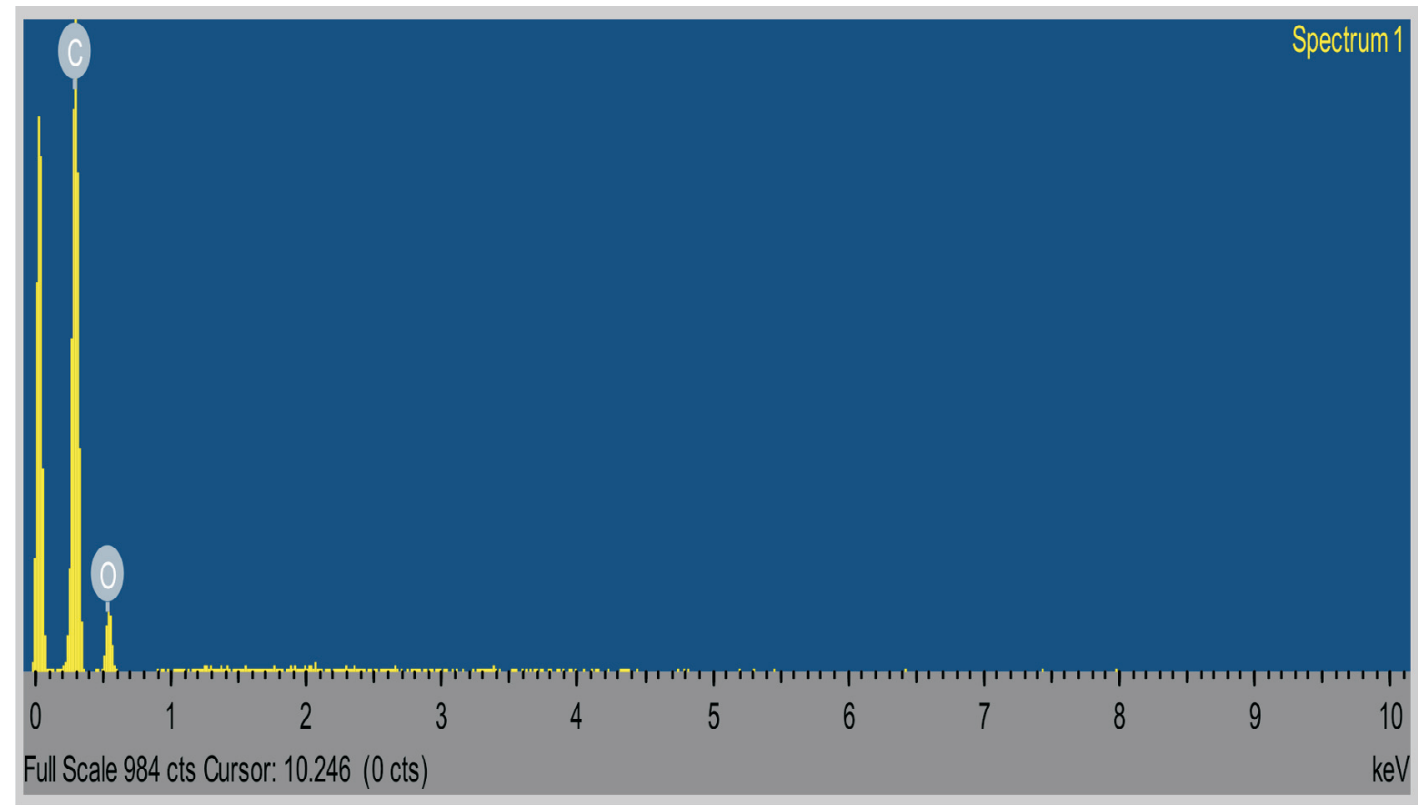

Figure 2 EDX spectra of activated carbon moringa pod (AMP).
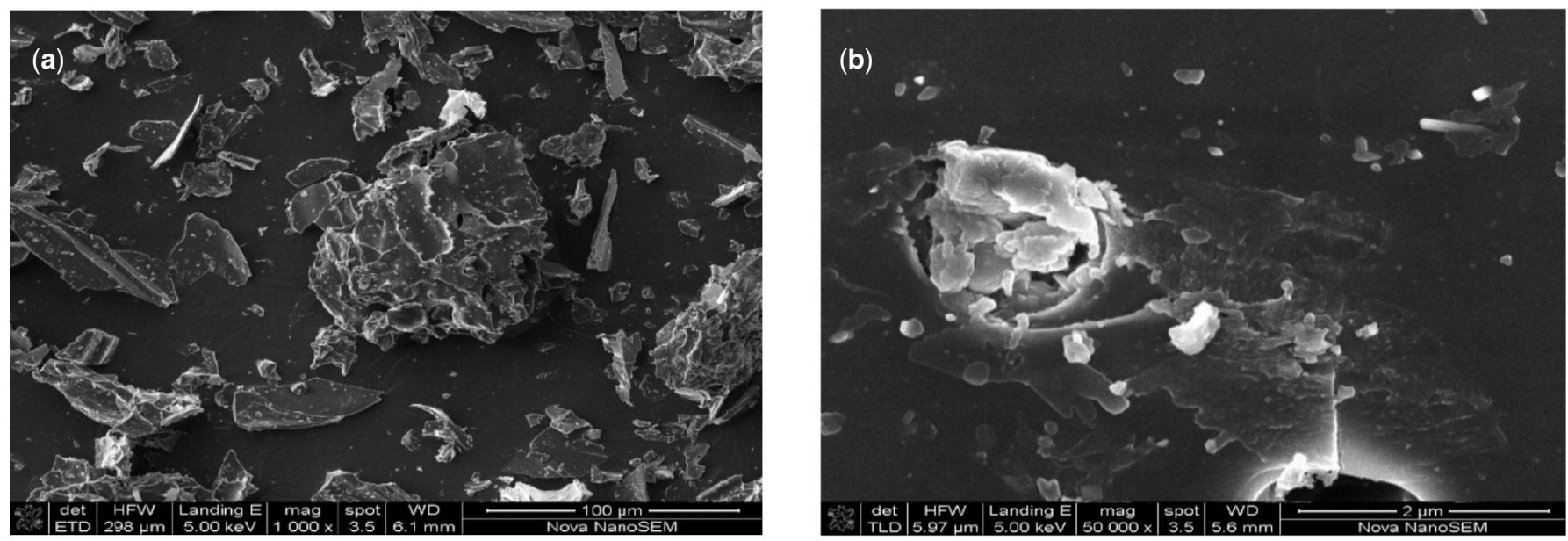

Figure 3 (a) SEM image of AMP at $\times 1000$. (b) SEM image of AMP $\times 50000$.

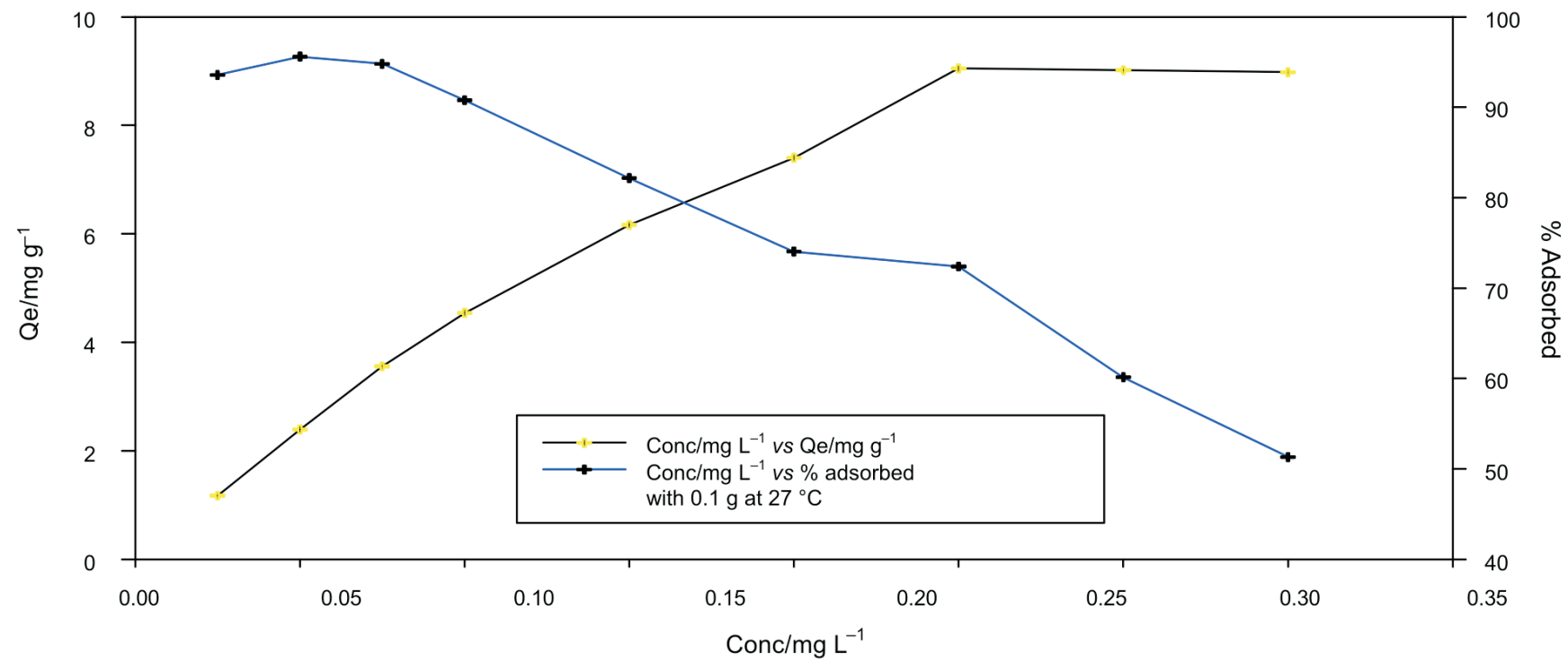

Figure 4 Graph of $\mathrm{Q}_{\mathrm{e}}\left(\mathrm{mg} \mathrm{g}^{-1}\right)$ and percentage adsorbed vs concentration $\left(\mathrm{mg} \mathrm{L}^{-1}\right)$ for AMP. 


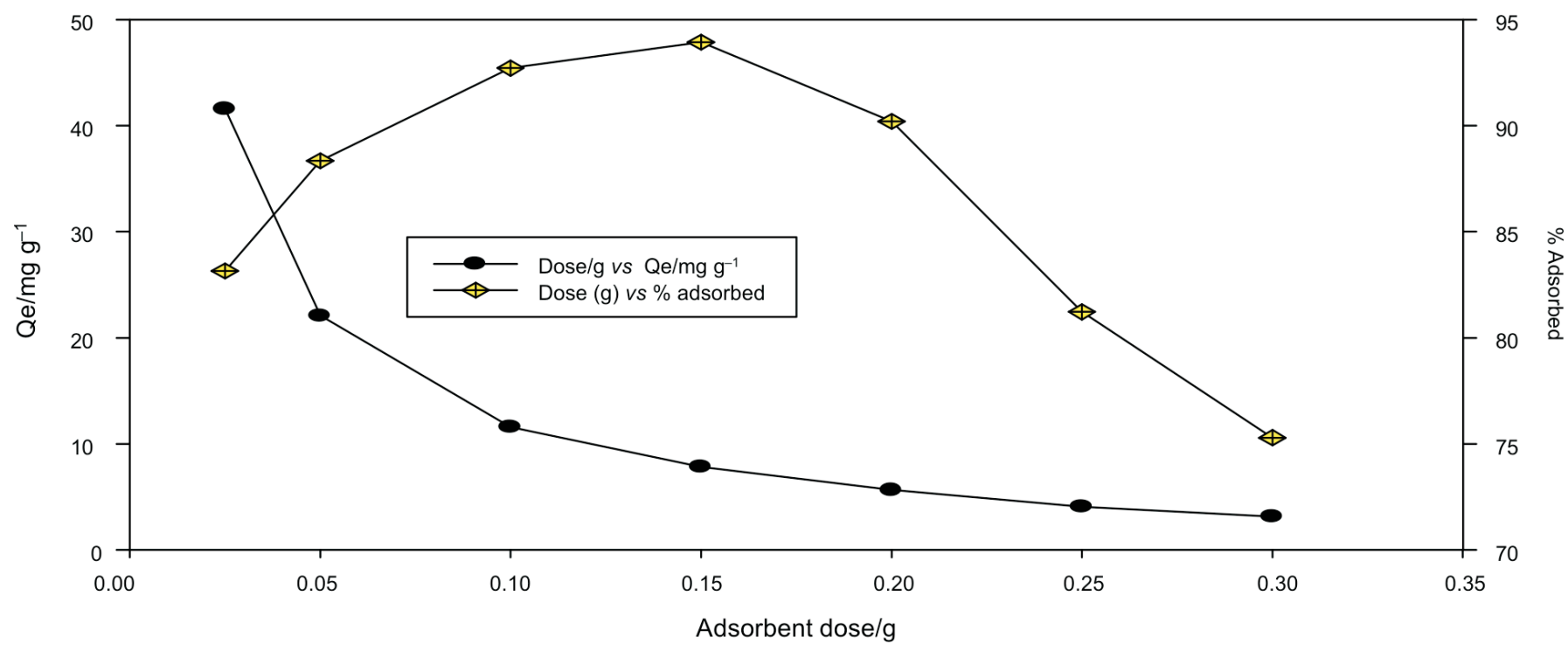

Figure 5 Graph of Qe $\left(\mathrm{mg} \mathrm{g}^{-1}\right)$ and percentage adsorbed vs adsorbent dose (g) for AMP.

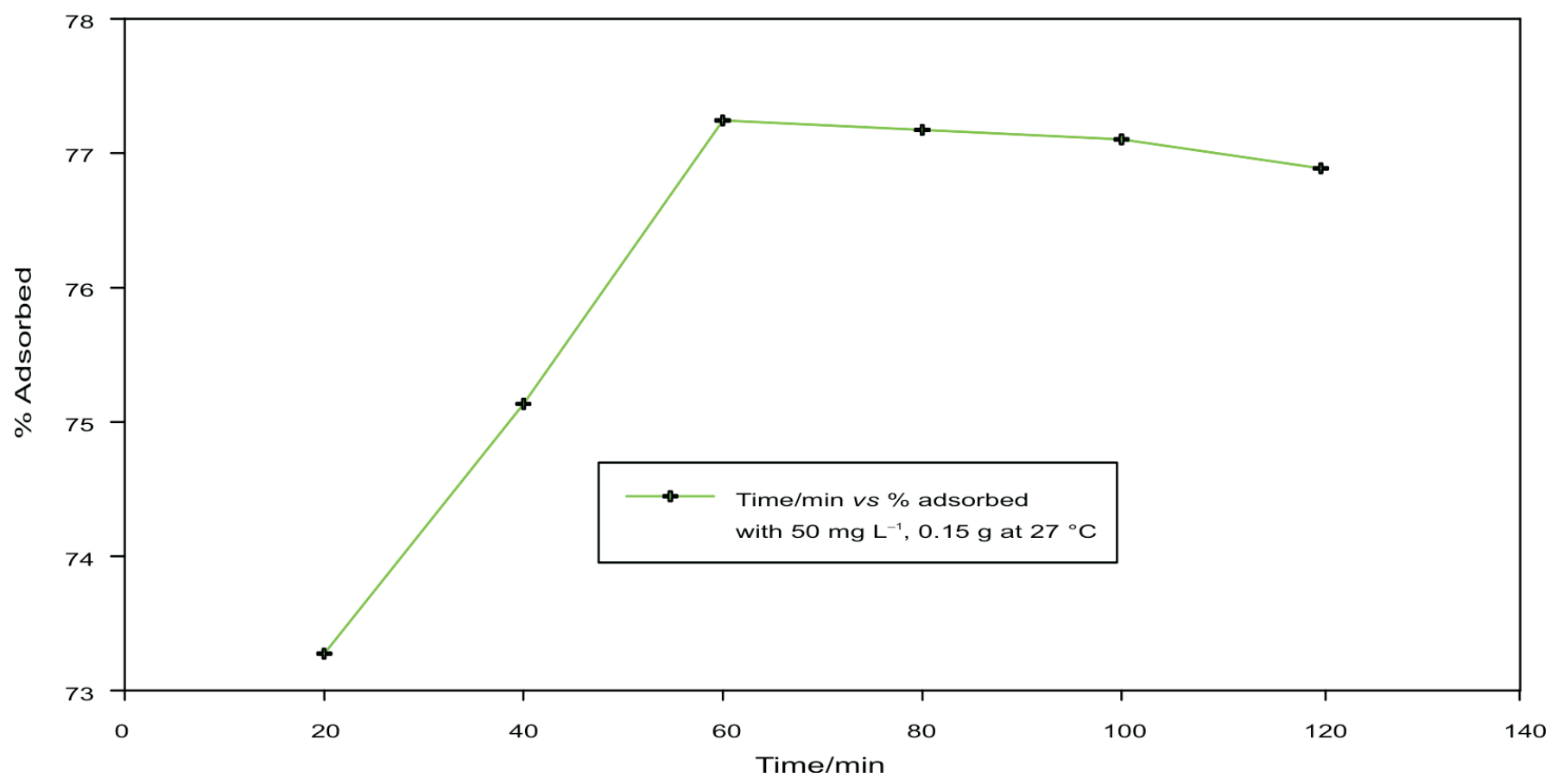

Figure 6 Graph of percentage adsorbed $v$ s contact time for AMP.

there was no considerable transformation as the constant percentage removal tends to be observed despite an improvement in the contact time. The reduction in the percentage dye removal en route towards the end of experiment signifies the feasible monolayer of the adsorbate on the external surface and pores of the adsorbent. This causes pore diffusion onto interior surface of the adsorbent particle. ${ }^{27}$ Million et al.${ }^{28}$ reported similar observation for the sorption capacity of methylene blue from aqueous solution onto untreated Parthenium hystrophorous weed.

\subsubsection{Effect of $p H$}

The influence of initial $\mathrm{pH}$ on adsorption percentage of $\mathrm{MB}$ dye was examined over a range of $\mathrm{pH}$ values from 2 to 12 and the graph is shown in Fig. 7. At low $\mathrm{pH}$, there is an increase in the percentage of removal indicating that the adsorbent showed good adsorption competence in the acidic medium than in the basic medium. This is because it was observed that towards the end of the experiment and after the $\mathrm{pH} 8$ point, the percentage dye removed tends to decrease gradually for the adsorbent AMP. Incremental dye removal was not noticed beyond $\mathrm{pH} 8$ and was selected for further studies. The finding obtained in this study is in line with the work reported on dye removal from textile wastewater using orange peels. ${ }^{26}$

\subsubsection{Effect of Temperature}

It was observed from the experiment that an increase in the temperature apparently increases the removal percentage of methylene blue. As the temperature increases from $30{ }^{\circ} \mathrm{C}$ to $55^{\circ} \mathrm{C}$, there is an increase in the quantity adsorbed from 86.47 to $88.05 \%$ (Fig. 8). This may be as a result of increase in the mobility of large dye ion with temperature. An increasing number of molecules may also acquire sufficient energy to undergo an interaction with active sites on the surface of the adsorbent. This study was in agreement with some work reported by Hashem and $A \min ^{29}$ on the adsorption of methylene blue by activated carbon derived from various fruit peels. 


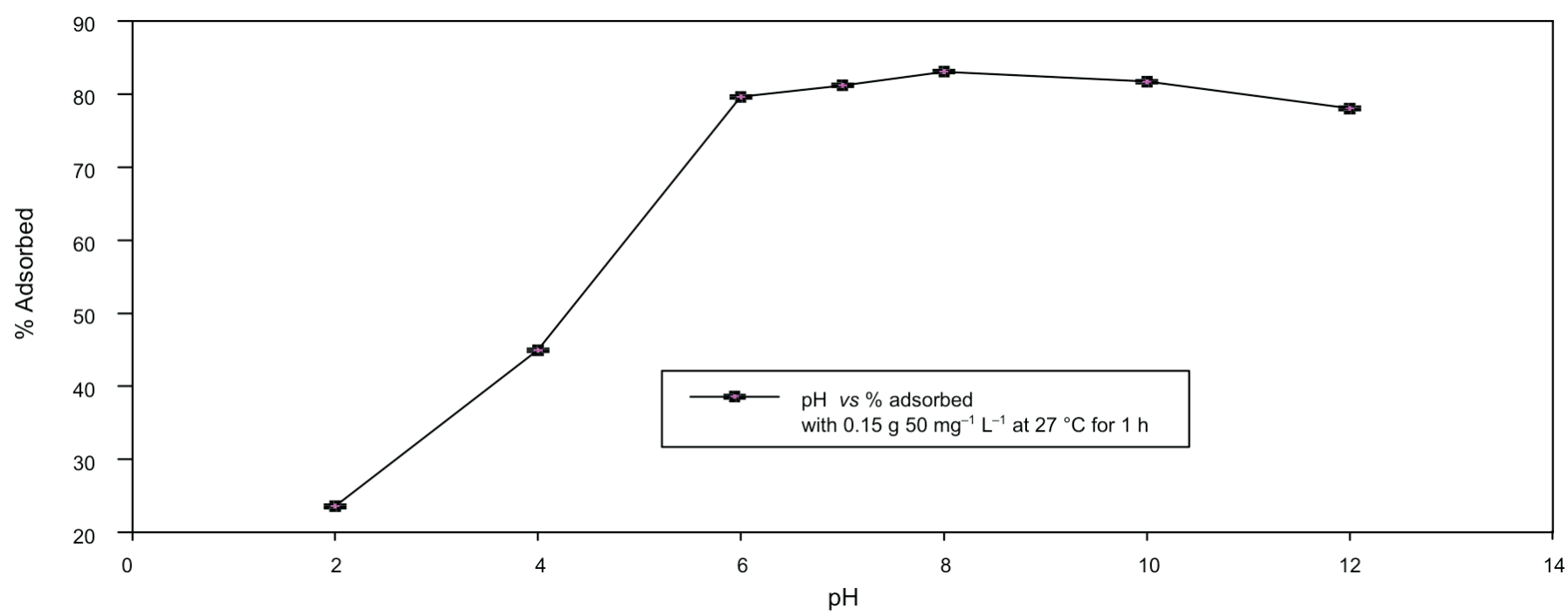

Figure 7 Graph of percentage adsorbed vs $\mathrm{pH}$ for AMP.

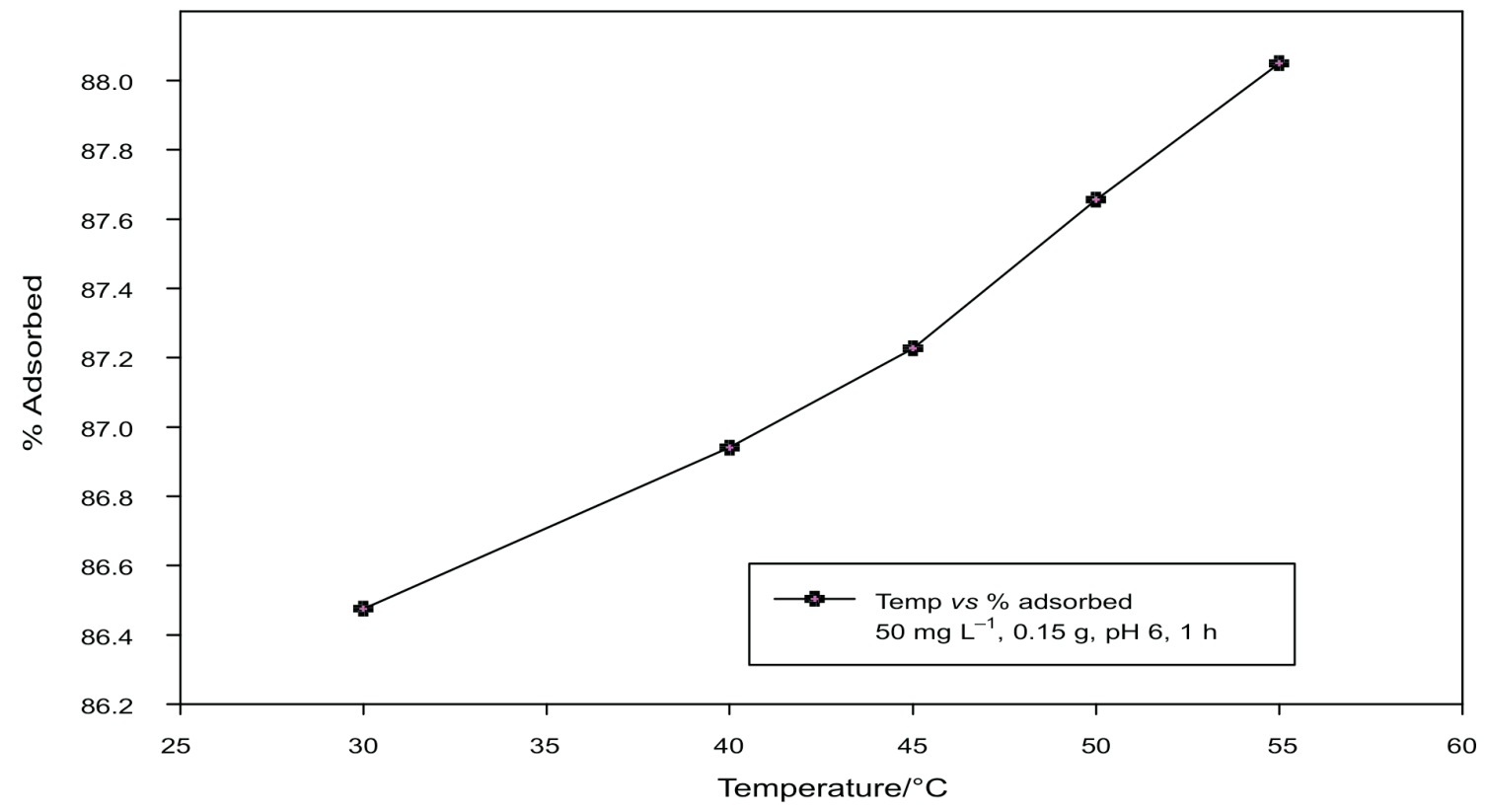

Figure 8 Graph of percentage adsorbed $v$ s temperature for AMP.

\subsection{Adsorption Isotherm}

Several models have been reported by different researchers to show equilibrium relationships between sorbent and sorbate. The most commonly-employed models are the Langmuir and Freundlich adsorption models. In this study, to describe the relationship between the amount of methylene blue and its equilibrium concentrations, both models were employed.

\subsubsection{Langmuir Isotherm}

The graph of the Langmuir adsorption is plotted in Fig. 9. It can

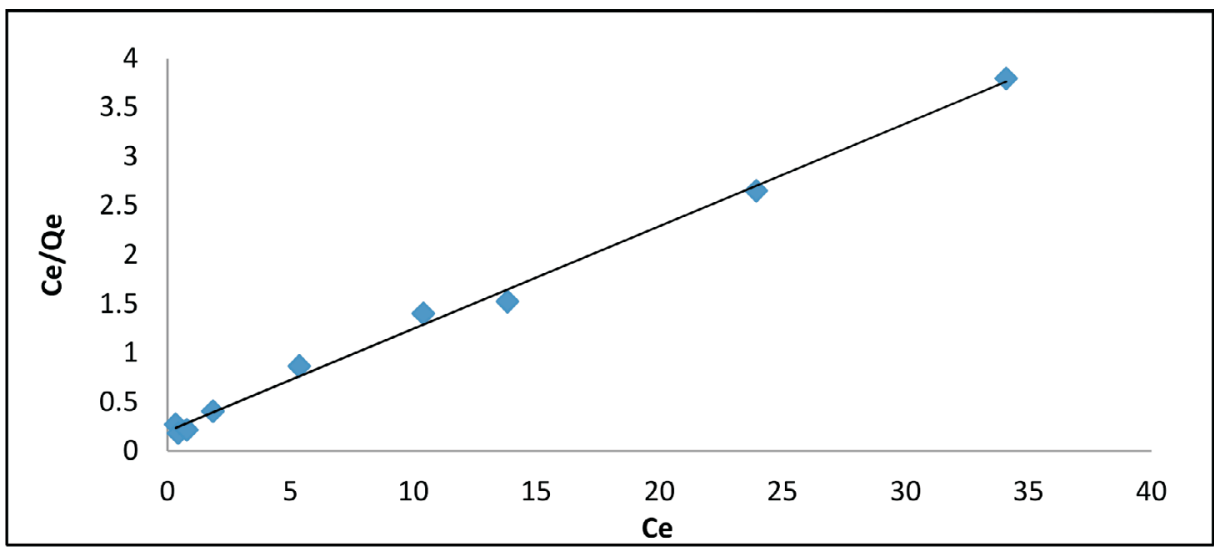

Figure 9 Langmuir adsorption isotherm of methylene blue onto AMP. 
be shown from the isotherm parameters (Table 3), that the adsorption efficiency of methylene blue from aqueous medium onto AMP is favourable as the $R_{L}$ value obtained is less than 1 and the adsorption data fitted well into Langmuir isotherm as the $\mathrm{R}^{2}$ value obtained for AMP is 0.9958 .

In comparison, the $R_{L}$ value (0.0391) obtained for AMP is lower than those reported by Inyinbor et al..$^{30}(0.19)$ in the 'Kinetics, isotherms and thermodynamic modelling of liquid phase adsorption of Rhodamine B. dye onto Raphia hookerie fruit epicarp' and Dada et al. ${ }^{31}(0.133)$ in the 'Langmuir, Freundlich, Temkin and Dubinin - Radushkevich isotherms studies of equilibrium sorption of $\mathrm{Zn}^{2+}$ onto phosphoric acid modified rice

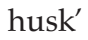

Table 3 Langmuir isotherm parameters for adsorption of MB onto AMP.

\begin{tabular}{cc}
\hline Langmuir parameters & AMP \\
\hline $\mathrm{R}^{2}$ & 0.996 \\
$\mathrm{~K}_{\mathrm{L}} / \mathrm{L} \mathrm{g}^{-1}$ & 0.551 \\
$\mathrm{q}_{\mathrm{m}} / \mathrm{mg} \mathrm{g}^{-1}$ & 9.578 \\
$\mathrm{R}_{\mathrm{L}}$ & 0.039 \\
\hline
\end{tabular}

\subsubsection{Freundlich Isotherm}

In this study, the values obtained for $\mathrm{K}_{\mathrm{f}}, \mathrm{R}^{2}$ and $\mathrm{n}$ are 2.960, 0.8858 and 2.6385 , respectively, as shown in Table 4 . The slope from the Freundlich plot ranges between 0 and 1 adsorption intensity or surface heterogeneity (Fig. 10). The heterogeneity increases as the values get closer to zero. A value below unity implies chemisorptions process as reported by Haghseresht and $\mathrm{Lu}^{32}$. Whereas the $\mathrm{K}_{\mathrm{f}}$ and $\mathrm{n}$ values obtained in this study are higher than the ones obtained by Sachin and Gaikwad ${ }^{33}(0.071$ and 0.9).

\subsubsection{Temkins Isotherm Model}

In this model, the value of correlation coefficient $\mathrm{R}^{2}$ obtained was establish to be 0.974 and Temkin isotherm constant $B_{T}$

Table 4 Freundlich isotherm parameters for adsorption of MB onto AMP.

\begin{tabular}{lc}
\hline Freundlich parameters & Activated carbon \\
\hline $\mathrm{K}_{\mathrm{f}}$ & 2.960 \\
$\mathrm{R}^{2}$ & 0.885 \\
$\mathrm{n}$ & 2.638 \\
$(1 / \mathrm{n})$ & 0.379 \\
\hline
\end{tabular}

obtained is 4352.12 (Table 5; Fig. 11), which is related to heat of sorption, indicating physicochemical nature of the sorption process.

Table 5 Temkin isotherm parameters for adsorption of MB onto AMP.

\begin{tabular}{cc}
\hline Temkin parameters & AMP \\
\hline $\mathrm{R}^{2}$ & 0.974 \\
$\mathrm{~A}_{\mathrm{T}} / \mathrm{L} \mathrm{g}^{-1}$ & 0.029 \\
$\mathrm{~B}_{\mathrm{T}} / \mathrm{mg} \mathrm{g}^{-1}$ & 4352.12 \\
\hline
\end{tabular}

\subsection{Adsorption Kinetics}

\subsubsection{Pseudo-First-Order Kinetic Model}

From the kinetic plot (Fig. 12) and Table 6, it can be deduced that the adsorption process did not fit well into pseudofirst-order as the $\mathrm{R}^{2}$ value (0.4489) obtained is very low compared to the other adsorption kinetic models.

\subsubsection{Pseudo-Second-Order Kinetic Model}

It was revealed in Fig. 13 and Table 7, that the adsorption process followed pseudo-second-order kinetic model as the $\mathrm{R}^{2}$ value obtained is 0.999 . Similar observations have been reported in the adsorption of methylene blue onto dehydrated wheat bran carbon by Özer and Dursun, ${ }^{34}$ and also in experimental study of methylene blue adsorption from aqueous solutions onto carbon nano tubes by Shahryari et al..$^{35}$

\subsection{Thermodynamic Studies}

The thermodynamic plots are shown in Fig. 14, and the values obtained for $\Delta \mathrm{G}^{0}, \Delta \mathrm{S}^{0}$ and $\Delta \mathrm{H}^{0}$ at $313 \mathrm{~K}$ are $-0.295 \mathrm{KJ} \mathrm{mol}^{-1}$, $0.0158 \mathrm{KJ} \mathrm{mol}^{-1}$ and $4.648 \mathrm{KJ} \mathrm{mol}^{-1}$, respectively, as shown in Table 8. It is clear that reaction is spontaneous in nature as $\Delta \mathrm{G}^{0}$ values for methylene blue onto AMP is negative for a spontaneous process under the applied conditions. The decrease in $\Delta G^{0}$ (i.e increase negative) values with increase in temperature indicated more efficient adsorption at higher temperature. This is because at higher temperature, ions are easily desolvated and therefore their adsorption becomes more favourable. ${ }^{36-37}$

A positive $\Delta \mathrm{H}^{0}$ and $\Delta \mathrm{S}^{0}$ values confirmed that the adsorption processes were endothermic and showed the increase in the degree of randomness during the adsorption process. This type of adsorption can be explained in terms of the magnitude of $\Delta \mathrm{H}^{0}$. The heat evolved during physisorption generally lies in the range of 2.1-20.9 $\mathrm{KJ} \mathrm{mol}^{-1}$, while the heat of chemisorption falls

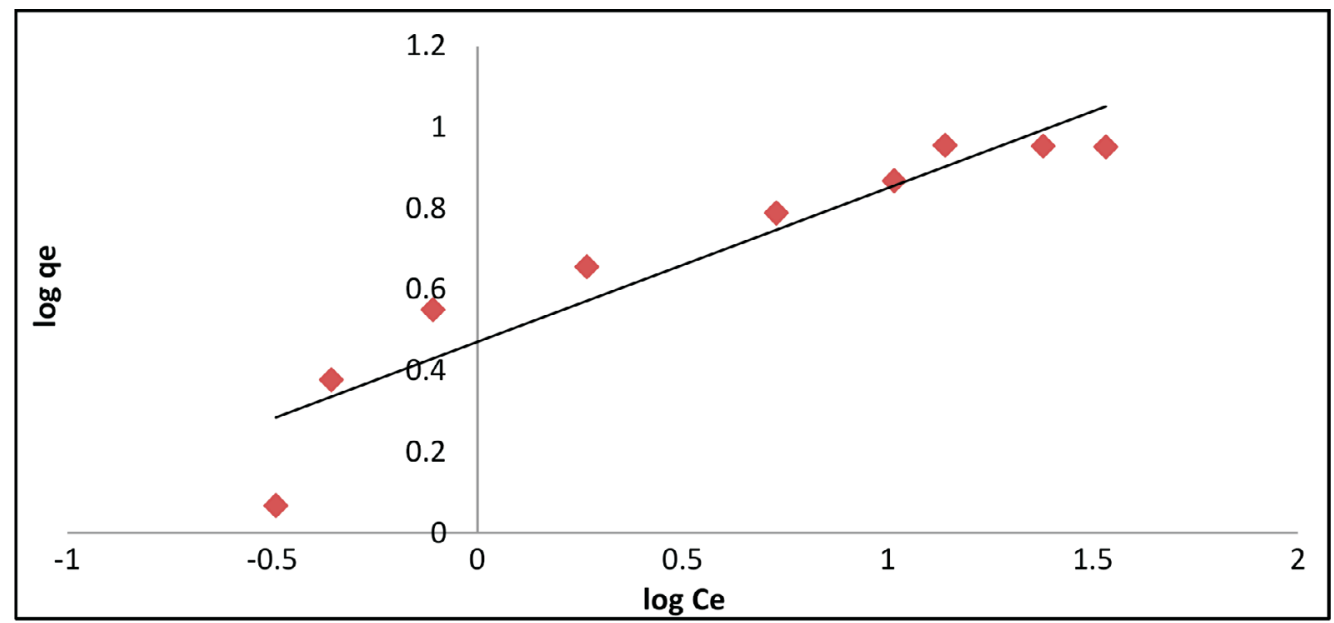

Figure 10 Freundlich isotherm plot of adsorption of methylene blue onto AMP. 


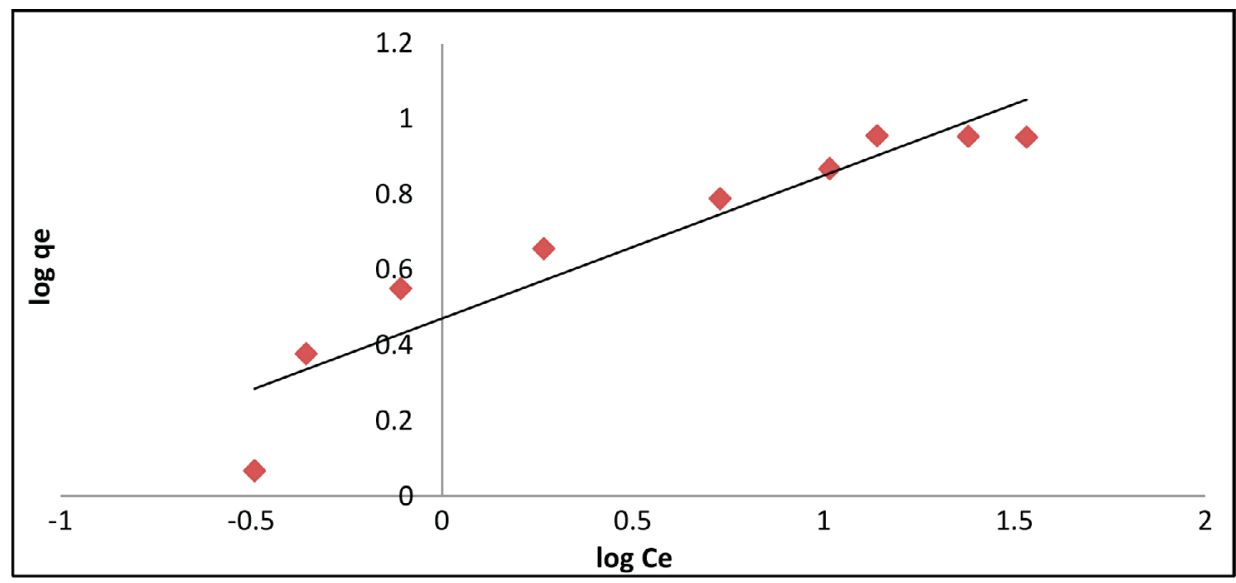

Figure 11 Temkin isotherm plot of methylene blue onto AMP.

Table 6 Parameters of pseudo-first-order kinetic model for adsorption of methylene blue onto acid modified activated carbon (AMP).

\begin{tabular}{cc}
\hline Pseudo-first-order parameters & Activated carbon \\
\hline $\mathrm{R}^{2}$ & 0.448 \\
$\mathrm{q}_{\mathrm{e}} / \mathrm{mg} \mathrm{g}^{-1}$ & 0.879 \\
$\mathrm{~K}_{1} / \mathrm{mg} \mathrm{g}^{-1}$ & 0.036 \\
\end{tabular}

Table 7 Parameters of pseudo-second-order kinetic model for adsorption of methylene blue onto activated carbon moringa pod (AMP).

\begin{tabular}{cc}
\hline Pseudo-first-order parameters & AMP \\
\hline $\mathrm{R}^{2}$ & 0.986 \\
$\mathrm{q}_{\mathrm{e}} / \mathrm{mg} \mathrm{g}^{-1}$ & 6.485 \\
$\mathrm{~K}_{2} / \mathrm{g} \mathrm{mg}^{-1} \mathrm{~min}^{-1}$ & 0.147 \\
$\mathrm{~h} / \mathrm{mg} \mathrm{g}^{-1} \mathrm{~min}^{-1}$ & 6.184 \\
\hline
\end{tabular}

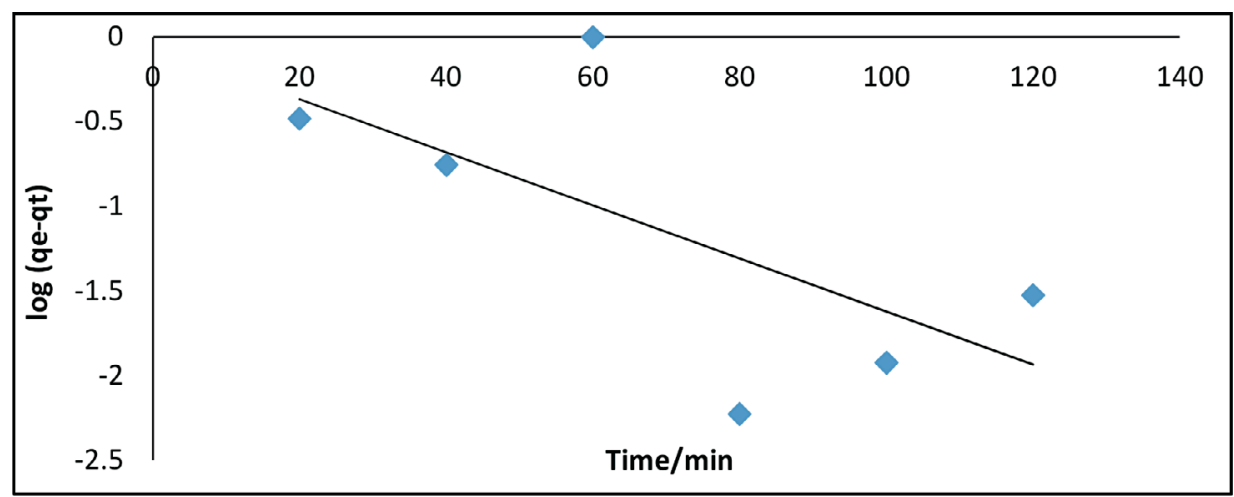

Figure 12 Pseudo-first-order plot of adsorption of methylene blue onto AMP.

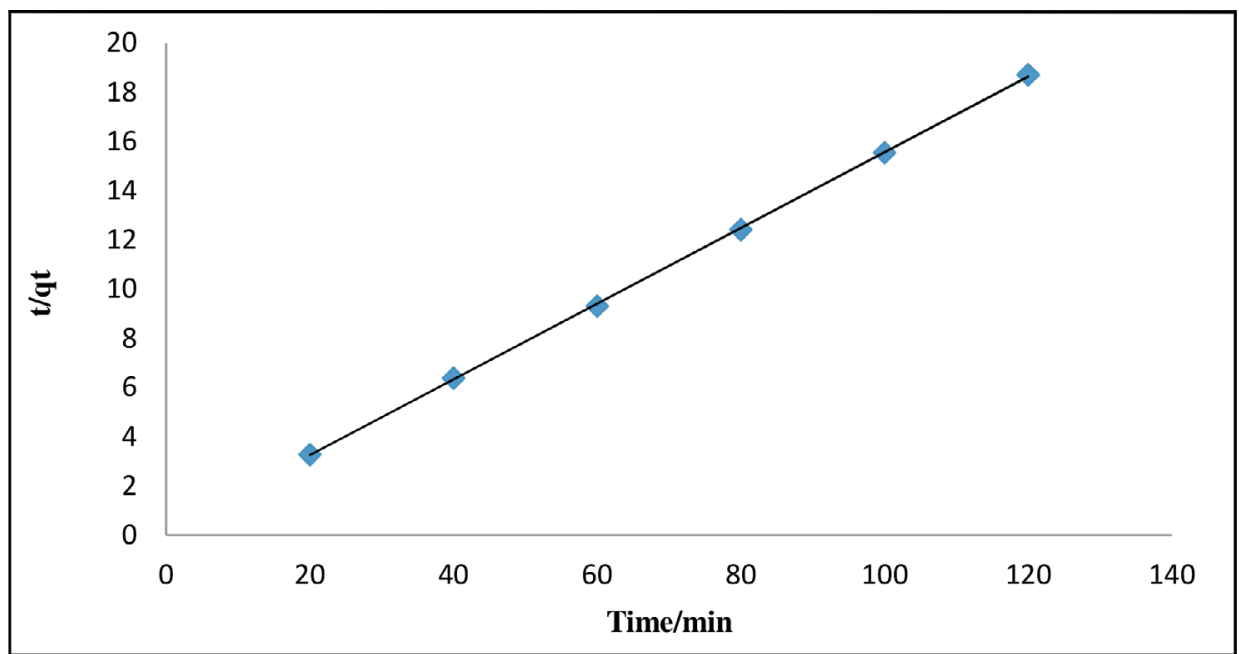

Figure 13 Pseudo-second-order plot of adsorption of methylene blue onto AMP. 


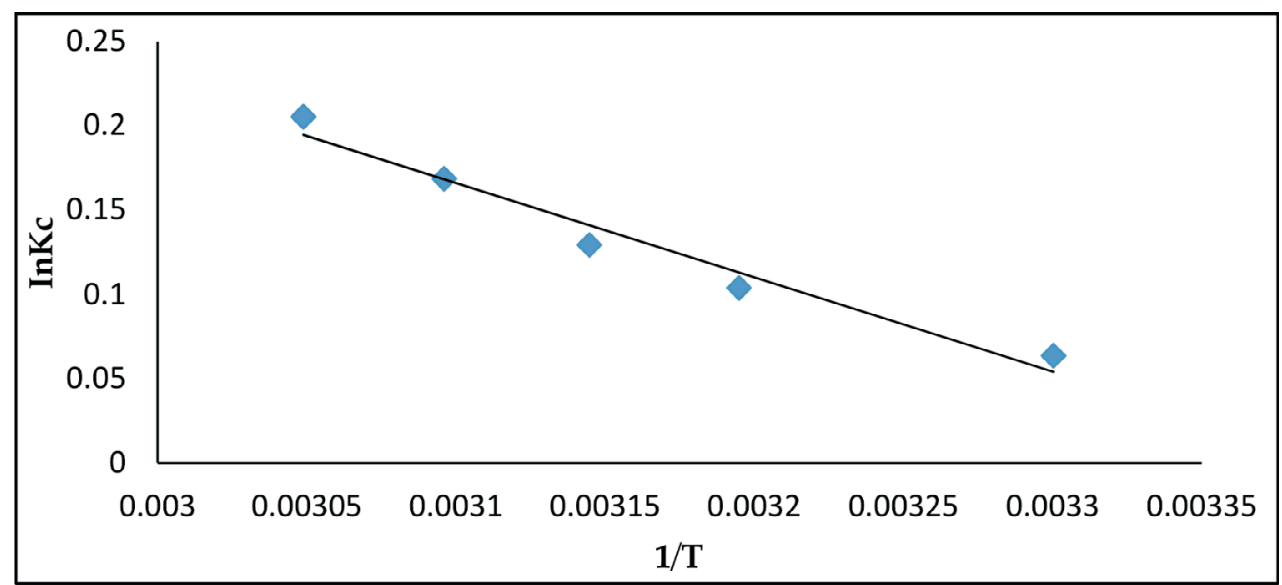

Figure 14 Thermodynamic plot of adsorption of methylene blue onto AMP.

Table 8 Thermodynamic parameters of methylene blue onto AMP.

\begin{tabular}{cccc}
\hline Temperature $/ \mathrm{K}$ & $\Delta \mathrm{G}^{0} / \mathrm{kj} \mathrm{mol}^{-1}$ & $\Delta \mathrm{S}^{0} / \mathrm{kj} \mathrm{mol}^{-1}$ & $\Delta \mathrm{H}^{0} / \mathrm{kj} \mathrm{mol}^{-1}$ \\
\hline 303 & -0.139 & & \\
313 & -0.297 & +0.015 & +4.648 \\
318 & -0.376 & & \\
323 & -0.450 & & \\
328 & -0.534 & & \\
\hline
\end{tabular}

into a range of $80-200 \mathrm{KJ} \mathrm{mol}^{-1} \cdot{ }^{38}$ The adsorption of methylene blue onto AMP may be attributed to a physical adsorption process.

\section{Conclusion}

This study shows that the adsorption capacity of adsorbent can actually be affected by initial concentration of the adsorbate, adsorbent dose, contact time and temperature. Also, the percentage removal of $\mathrm{MB}$ increases with the increase in initial concentration, adsorbent dosage, contact time and temperature. Hence, activated carbon moringa pod (AMP) is a potential adsorbent that can remove colourants from wastewater through an adsorption process, i.e. physisorption. From this study, it is, therefore, demonstrated that adsorbents produced from low cost agricultural materials (moringa pod husk) can be used effectively to remove colourants from wastewater.

\section{References}

1 Z. Shengli, W. Zhikai, Z. Yulei, P. Hongyu and T. Lichun, Adsorption of methylene blue on organosolv lignin from rice straw, Procedia Environ. Sci., 2016, 31, 3-11.

2 P. Tarapitakcheevin, P. Weerayutsil and K. Khuanmar, Adsorption of acid dye on activated carbon prepared from water hyacinth by sodium chloride activation, Ind. Eng. Chem. Fund., 2013, 7, 83-90.

3 K. Kadirvelu, M. Kavipriya, C. Karthika, M. Radhika, N. Vennilamani and S.Pattabhi, Utilization of various agricultural wastes for activated carbon preparation and application for the removal of dyes and metal ions from aqueous solutions, J. Biores. Technol., 2003, 87, 129-132.

4 P. Pandit and S. Basu, Removal of ionic dyes from water by solvent extraction using reverse micelles, J. Am. Chem. Soc., 2004, 38(8), 2435-2442.

5 N.R. Nicomel, K. Leus, K. Folens, P. Van Der Voort and G.D. Laing, Technologies for arsenic removal from water: current status and future perspectives, Int. J. Environ. Res. Public Health, 2016, 13, 62, $1-24$.

6 K.S. Bharathi and S.T. Ramesh, Removal of dyes using agricultural waste as low cost adsorbents, Appl. Water Sci., 2013, 3, 773-790.

7 C. Song, S. Wu, M. Cheng, P. Tao, M. Shao, G. and Gao, Adsorption studies of coconut shell carbons prepared by $\mathrm{KOH}$ activation for removal of lead (II) from aqueous solutions, Sustainability, 2014, 6(1), 86-98.

8 Z. Ying, R. Zheng, Z. Jiaying, M. Fang, Z. Yinchao and M. Qingjuan, Characterization of $\mathrm{H}_{3} \mathrm{PO}_{4}$ treated rice husk adsorbent and adsorption of copper (II) from aqueous solution, BioMed. Res. Int., 2014, 1-8.

9 O. Abdelwahab and N.K.Amin, Adsorption of phenol from aqueous solutions by Luffa cylindrica fibers: kinetics, isotherm and thermodynamic studies. Egypt. J. Aquat, Res., 2013, 39(4), 215-223.

10 O.S. Bello, K.A. Adegoke and O.O. Akinyunni, Preparation and characterization of a novel adsorbent from Moringa oleifera leaf, Appl. Water Sci., 2015, 1-11.

11 K.Y. Foo and B.H. Hameed, Insights into the modelling of adsorption isotherm systems, Chem. Eng. J., 2010, 156, 2-10.

12 C. Aharoni and M. Ungarish, Kinetics of activated chemisorption. Part 2, Theoretical models, J. Chem. Soc. Faraday Trans., 1977, 73, 456-464.

13 M. Hema, M. and S. Arivoli, Studies on adsorption efficiency and kinetics of dye removal from textile effluent using some natural bio-adsorbent, Int. J. Phys. Sci., 2007, 2(1), 010-017.

14 E.S. Abechi, C.E. Gimba, A. Uzairu and J.A. Kagbu, Kinetics of adsorption of methylene blue onto activated carbon prepared from palm kernel shell, Arch. Appl. Sci. Res., 2011, 3(1), 154-164.

15 S. Qaiser, R.S. Anwar and U. Muhammad, Biosorption of lead(II) and chromium(VI) on groundnut hull: equilibrium, kinetics and thermodynamics study. Elect. J. Biotech., 2009, 12, 4, 0717-3458.

16 P.C. Madu and L. Lajide, Physicochemical characteristics of activated carbon derived from melon seed husk, J. Chem. Pharm. Res. 2013, 5(5), 94-98.

17 B. Sivakumar, C. Kannan and S. Karthikeyan, Preparation and characterization of activated carbon prepared from Balsamodendron caudatum wood waste through various activation processes, Rasayan J. Chem., 2012, 5(3): 321-327.

18 A. Shukla, Y.H. Zhang, P. Dubey and S.S. Shukla, The role of saw dust in the removal of unwanted materials from water, J. Hazard. Mater. 2002, 95(12), 137-152.

19 V. Srihari and D. Ashutosh, Adsorption of phenol from aqueous media by an agro waste Hemidesmus indicus based activated carbon, Appl. Ecol. Environ. Res., 2009, 7(1), 13-23.

20 R.A. Wuana, L. Leke, D.A. Okibe and M. Okei, Aqueous phase adsorption of $\mathrm{Cu}$ (II) and Co (II) ions from single and bisolute solutions onto base-treated and carbonized rice husks, Niger. J. Appl. Sci., 2009, 27, 129-136.

21 P. Sugumaran, V.P. Susan, P. Ravichandran and S. Seshadri, Production and characterization of activated carbon from banana empty fruit bunch and Delonix regia fruit pod, J. Sustain. Energy Environ., 2012, 3, 125-132.

22. G.B. Adebayo, H.I. Adegoke, W. Jamiu, B.B. Balogun and A.A. Jimoh, Adsorption of $\mathrm{Mn}$ (II) and $\mathrm{Co}(\mathrm{II})$ ions from aqueous solution using maize cob activated carbon: kinetics and thermodynamics studies, J. Appl. Sci. Environ. Manage., 2015, 19(4), 734-748.

23 B. Kannamba, K.L. Reddy, B.V. AppaRao, Removal of $\mathrm{Cu}$ (II) from aqueous solutions using chemically modified chitosan, J. Hazard. Mater., 2010, 175, 939-948.

24 H. Deng, G. Zhang, X. Xu, G. Tao and J. Dai, Optimization of preparation of activated carbon from cotton stalk by microwave assisted 
phosphoric acid - chemical activation, J. Hazard. Mater., 2010, 182, 217-224.

25 N.F. Cardoso, E.C. Lima, I.S. Pinto, C.V. Amavisca, B. Royer, R.B. Pinto, W.S. Alencar and S.F.P. Pereira, Application of cupuassu shell as biosorbent for the removal of textile dyes from aqueous solution. J. Environ. Manage., 2011, 92, 1237-1247.

26 F.B. Abdur Rahman, M. Akter and A.M. Zainal, Dyes removal from textile wastewater using orange peels, Int. J. Sci. Technol. Res., 2013, 2, $47-50$.

27 R.M. Nageswara, R.Y. Hanumantha, C. Chakrapani, B.C. Suresh, R.B.V. Rajeswara, P. Haritha and R.K. Somasekhara, Adsorption studies of methylene blue dye using prepared low-cost activated Kaza's carbons, J. Chem. Pharm. Res., 2011, 3(5), 363-375.

$28 \mathrm{M}$. Million and L. Belisti, Removal of methylene blue $(\mathrm{Mb})$ dye from aqueous solution by bioadsorption onto untreated Parthenium hystrophorous weed, Mod. Chem. appl, 2014, 2, 4.

29 F.S. Hashem and M.S. Amin, Adsorption of methylene blue by activated carbon derived from various fruit peels, Desalin. Water Treat., 2016, 57, 47, 22573-22584.

30 A.A. Inyinbor, F.A. Adekola and G.A. Olatunji, Kinetics, isotherms and thermodynamic modelling of liquid phase adsorption of Rhodamine B dye onto Raphia hookerie fruit epicarp, Water Res. Ind., 15, 14-27.

31 A.O. Dada, A.P. Olalekan, A.M. Olatunya and O. Dada, Langmuir Freundlich, Temkin and Dubinin-Radushkevich isotherms studies of equilibrium sorption of $\mathrm{Zn}^{2+}$ unto phosphoric acid modified rice husk, IOSR J. Appl. Chem., 2012, 3(1), 38-45.

32 F. Haghseresht and G. Lu, Adsorption characteristics of phenolic compounds onto coal reject-derived adsorbents, Energy Fuels, 1988, 12, 1100-1107.

33 M.K. Sachin and R.W. Gaikwad, Removal of zinc ions from industrial effluent by using cork powder as adsorbent, Int. J. Chem. Eng., Appl. 2011, $2,3$.

34 A. Özer and G. Dursun, Removal of methylene blue from aqueous solution by dehydrated wheat bran carbon., J. Hazard. Mater., 2007, 146, 262-269.

35 Z. Shahryari, S.G. Ataallah and A. Mehdi, Experimental study of methylene blue adsorption from aqueous solutions onto carbon nanotubes, Int. J. Water Res. Environ. Eng., 2010, 2(2), 016-028.

$36 \mathrm{C}$. Chen and $\mathrm{X}$. Wang, Adsorption of $\mathrm{Ni}^{2+}$ from aqueous solution using oxidized multi-wall carbon nanotubes, Ind. Eng. Chem. Res., 2006, 45, 9144-9149.

37 J.A. Hefne, W.K. Mekhemer, N.M. Alandis, O.A. Aldayel and T. Alajyan, Kinetic and thermodynamic study of the sorption of $\mathrm{Pb}^{2+}$ from aqueous solution to the natural and treated bentonite, Int. I. Phys. Sci., 2008, 3, 11, 281-288.

38 Z.A. AL-Anber and M.A. AL-Anber, Thermodynamics and kinetic studies of iron(III) adsorption by olive cake in a batch system, J. Mex. Chem, Soc., 2011, 52, 2, 108-115. 